\title{
Performing 'Readings': The Interplay of Theatre And Digital Comics In Tezuka
}

\author{
MATHIAS P. BREMGARTNER, University of Berne
}

\begin{abstract}
The article investigates the intriguing interplay of digital comics and live-action elements in a detailed performance analysis of TeZukA (2011) by choreographer Sidi Larbi Cherkaoui. This dance theatre production enacts the life story of Osamu Tezuka and some of his famous manga characters, interweaving performers and musicians with large-scale projections of the mangaka's digitised comics. During the show, the dancers perform different 'readings' of the projected manga imagery: e.g. they swipe panels as if using portable touchscreen displays, move synchronously to animated speed lines, and create the illusion of being drawn into the stories depicted on the screen. The main argument is that TeZukA makes visible, demonstrates and reflects upon different ways of delivering, reading and interacting with digital comics. In order to verify this argument, the paper uses ideas developed in comics and theatre studies to draw more specifically on the use of digital comics in this particular performance.
\end{abstract}

\section{KEYWORDS}

Digital comics, manga, animation, theatre, Osamu Tezuka, Sidi Larbi Cherkaoui. 


\section{Introduction: Theatre meets comics}

Over the last few years, comics have become an important cultural influence for theatre. A broad spectrum of productions draw on the plots, characters, forms of expression and aesthetics of comics. These range from commercial productions such as the arena show Batman Live and the Broadway Musical Spider-Man - Turn Off the Dark, to city and state theatre performances such as Prinz Eisenherz. (Prince Valiant) and independent theatre productions such as Popeye's Godda Blues. ${ }^{1}$ A particularly interesting performance in this context is the dance theatre production TeZukA (2011). ${ }^{2}$ In TeZukA, Belgian-Moroccan choreographer Sidi Larbi Cherkaoui deals with the life story and the oeuvre of Japanese comics visionary Osamu Tezuka (1928-1989). The performance makes use of Tezuka's manga in the form of digitised comics, which are projected in a various forms onto an immense screen at the back of the stage.

This article examines the elaborate interplay of live-action elements and digital comics in a detailed performance analysis. The leading argument is that TeZukA makes visible, demonstrates and reflects upon different ways of delivering, reading and interacting with digital comics. This argument draws upon the specific mediality of theatre, that can be understood as "the simultaneous physical presence of the performer and the spectator in the same space in the moment of here and now' (Chapple and Kattenbelt 2006, 22). Accordingly, live performance is always constituted as a time-based interplay of actors and scenes on stage with an audience. In its performance, production and reception of theatre coincide and are mutually dependent. This specific mediality of theatre is not affected by the use of media. Instead, theatre is characterised by a 'fundamentally plurimedial structure' (Rajewsky 2010, 53) and has the potential 'to realize and represent all other media' (Balme 2008, 91). Even though the media that are employed in a performative situation are reframed differently and encoded as theatrical signs in the performance, they do not forfeit their own specific medial characteristics. Based on this medial condition, theatre is conceived 'as a hypermedium that [is] capable of incorporating, representing and on occasion even thematizing other media' (Balme 2008, 90). In order to show how TeZukA makes visible, demonstrates and reflects upon various forms of delivering, reading and interacting with digital comics, the article begins by explaining different aesthetic procedures of digital comics. Next, the dramaturgy and the theatrical as well as medial elements used in the performance are examined. Lastly, the article analyses the use of digital comics and the interplay with the actors on the basis of selected scenes of the performance.

\section{Aesthetic procedures of digital comics}

Digitalisation and the Internet have resulted in substantial changes in the creation, distribution and consumption of comics (cf. Gravett 2014, Hammel 2014 and Petersen 2011). The revolution of the medium of comics in terms of form and content, which Scott McCloud has predicted in Reinventing Comics (2001), the follow-up to his influential book Understanding Comics (1993), has failed to take place so far. However, the Internet and the digitalisation of

\footnotetext{
${ }^{1}$ Batman Live, directed by Anthony van Laast, premiered on $19^{\text {th }}$ July 2011 at O2-Arena Manchester; SpiderMan - Turn off the Dark, directed by Julie Taymor, premiered on $14^{\text {th }}$ June 2011 at Foxwoods Theatre New York; Prinz Eisenherz, directed by Caroline Stolz, premiered on $11^{\text {th }}$ June 2011 at Hessisches Staatstheater Wiesbaden; Popeye's Godda Blues, directed by Meret Matter, premiered on $22^{\text {th }}$ January 2010 at Schlachthaus Theater Bern.)

${ }^{2} T e Z u k A$, choreography by Sidi Larbi Cherkaoui, premiered on $6{ }^{\text {th }}$ September 2011 at Sadler's Wells Theatre London.
} 
comics have given rise to a number of new phenomena and terminologies such as webcomics, e-comics, hypercomics and motion comics (cf. Campbell 2006, Hammel 2014 and Jenkins 2012). All these different manifestations have in common that they exist as digital formats, be it as 'comics created specifically for digital display and distribution via the web' (Goodbrey $2012,187)$ or simply as 'digital remediations of comics originally designed for the printed page' (Goodbrey 2013, 188). In comparison to print comics, digital comics - used here as a collective term for all the manifestations named above - open up new possibilities: on the one hand in terms of the procedures with which readers are lead through sequentially arranged images, on the other hand with regard to the portrayal of the 'temporal map' (McCloud 2001, 207), i.e. the spatial arrangement of images which create tension 'between the stasis of an individual image and the spatio-temporal movement of the sequence' (Bukatman 2002, 134).

Digital comics are no longer bound to the page structure of print comics and can thus break fresh ground in terms of the arrangement and pacing of image sequences. Instead of showing a comic book page, the digital display can function as a window, which opens the view to a potentially endless 'temporal map' spreading in all directions. Thanks to this possibility of portrayal - Scott McCloud calls it the 'infinite canvas' (McCloud 2001, 222) - traditional panel layouts in print comics can be replaced by, for example, a long horizontal or vertical panel or an image sequence scrolling past in a constant flow of single panels. As Will Eisner points out, this arrangement of panels also affects the reading process:

The infinite canvas allows the reader to follow the flow of imagery and text by scrolling across a larger field designed by the storyteller. This format offers a wide range of image deployment and panel layout, but also involves participation by the reader via navigation control (Eisner 2008, 161).

In addition to this principle of the 'infinite canvas', digital comics have generated further new procedures, 'panel delivery' and 'guided view', which replace the page turn in print comics and guide the reader through image sequences. With panel delivery, the screen becomes a motionless stage on which panels appear either simultaneously or in succession. Through clicking, new panels are delivered, which supplement, replace or overlay the old. Unlike with panel delivery, the original page structure of comics remains intact with guided view. This procedure was developed in the course of the adaptation of print comic pages to smaller portable touchscreen displays. Guided view navigates the reader from panel to panel with the help of zooms and animated transitions when prompted by the reader's click or swipe. In addition to this animated transition between panels, the digital design of comics allows for inclusion of animated content as well as animation and movement of the panels themselves, for example regarding their size, form and positioning (Goodbrey 2013).

The application of these new possibilities of display and aesthetic procedures is varyingly marked in digital comics. While some digital comics hardly differ from print comics with regards to the design of the spatio-temporal structure, others make excessive use of the new possibilities, for example the inclusion of animation. This results in tension and flowing boundaries between digital comics and full animation. However, as Daniel Merlin Goodbrey points out, in order for sequentially arranged images to still function as comics it remains crucial that the reader is in control of the rate at which the available information is absorbed:

In digital comics, in order for the comic to still function as a comic, the rate at which information is received has to be determined by the reader. Just as in a print comic, this is determined by reading pace and the digital equivalent of the page turn, be that a click, a scroll or a swipe. By keeping control of advancement through the temporal map, 
control and creation of the fictional time represented in the comics remains with the reader (Goodbrey 2013, 195).

Following this line of argument, reader control is one of the defining differences between digital comics and animation in terms of spatio-temporal organisation and reception. While 'an active reader of the comic' (Goodbrey 2013, 195) determines the reading pace, a 'passive observer of the animation' (Goodbrey 2013, 195) cannot control its duration and frequency.

\section{Choreographing (digitised) manga}

In light of these explanations on the different means of portrayal and aesthetic procedures of digital comics and the understanding of theatre as a hypermedium, the article now turns to a detailed analysis of the interplay between live-action elements and digital comics in the dance theatre production TeZukA. This performance was made by choreographer Sidi Larbi Cherkaoui in collaboration with the Belgian dance theatre troupe Eastman Company and premiered on the $6^{\text {th }}$ of September 2011 at Saddler's Wells Theatre in London. TeZukA is Cherkaoui's choreographic homage to Japanese manga artist Osamu Tezuka, who is revered as the 'God of Manga' due to his immense influence on Japanese comics and culture (Gravett 2004, 24). In the performance, eleven dancers, three musicians and one calligrapher explore Tezuka's life story and cosmos of characters and stories, which encompasses ' 150.000 pages for 600 titles as well as some 60 animated works' (Gravett 2004, 24). To do that, the performance combines different languages, live music, martial arts, calligraphy, body painting and various dance styles, for example classical ballet, contemporary dance and hip hop. In addition to these elements, the performance uses video animations, which are projected onto a huge screen at the back of the stage. ${ }^{3}$

The dramaturgy of the performance, i.e. its development and structuring principles relating to potential effects (Kotte 2010, 170), constitutes itself as a loose succession of choreographic scenes which treat different aspects of Tezuka's biography and oeuvre. Cherkaoui's fascination for Tezuka's characters and stories guarantees the cohesion of content in the performance. On stage, Portuguese dancer Helder Seabra acts as Cherkaoui's alter ego, who mostly holds a manga book in his hands. Seabra's appearances frame and structure the dance theatre production. In the beginning, he sits on stage alone, deeply immersed in a volume of Astro Boy, a manga series named after Tezuka's most famous character. Together with other actors (for example the French performer Damien Jalet and the Norwegian dancer Guro Nagelhus Schia, who also sometimes appears with a manga in her hands), Seabra repeatedly introduces the audience to Tezuka's biography and cosmos of stories and characters. However, the performance does not tell the plots of Tezuka's manga, neither on screen nor on stage. Instead, it presents Tezuka's oeuvre through the enactment of selected characters on stage. Astro Boy, a robot who is powered by nuclear energy, is portrayed by dancer Kazutomi Kozuki with the typical naked upper body, red boots and black shorts of the manga character. Another famous character, the illegally practising doctor Black Jack, appears just as in the manga series of the same name, in a long black suit and a dyed strand of grey hair. In addition to these, less common characters are also enacted. Examples include the futuristic war robot Ambassador Magma, the seductive insect woman Joro Gumo, the traumatised girl Ayako, the

\footnotetext{
${ }^{3}$ The recording of a performance at Bunkamura Theatre in Tokyo in February 2012 serves as the basis for the following performance analysis. In terms of its dramaturgy and use of projections, this version differs from the one shown in London five months earlier. The video design for TeZukA was done by Japanese artist Taiki Ueda, and British musician and producer Nitin Sawhney composed the music for the dance theatre production.
} 
young lovers from Tezuka's unfinished epos Phoenix and the homosexual couple consisting of a serial killer and a priest from his series $M W$. In order to emphasise their different characteristics and aesthetics, the performance makes use of highly heterogenic dance styles for the portrayal of these characters. Thus, Astro Boy makes robot-like movements, while the couple from Phoenix use movements from classical ballet.

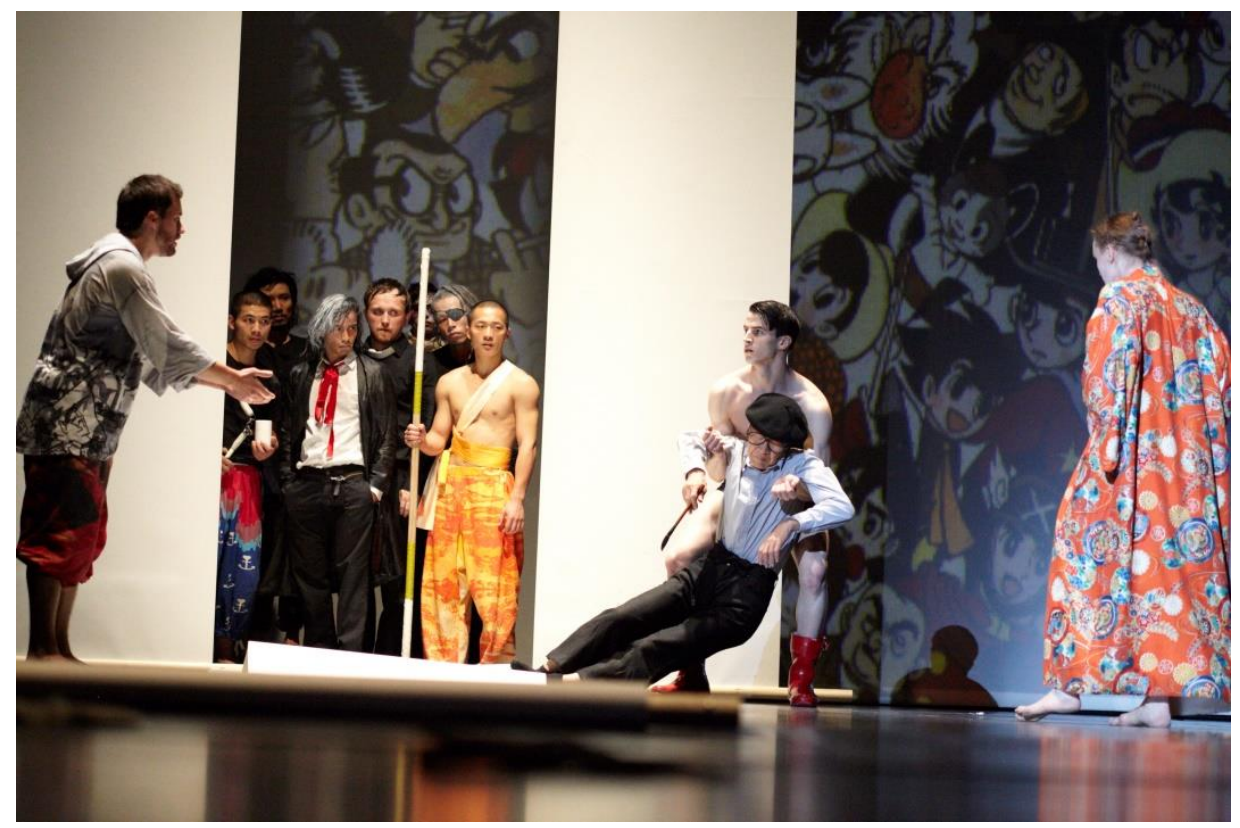

Figure 1. TeZukA, Sidi Larbi Cherkaoui (C) Koen Broos Eastman 2011.

Watched by Cherkaoui's alter ego (Helder Seabra, left) and some of the mangaka's characters standing in the background, Osamu Tezuka (enacted by calligrapher Tosui Suzuki) dies in the arms of Astro Boy (centre). ${ }^{4}$

In addition to the enactment of individual characters, the performance shows Tezuka's works in the form of digitised comics on a screen in the background that takes up the entire width of the stage. In many scenes animated panels and pages from Tezuka's manga are projected onto the screen. In addition to the titles already mentioned above, images from series such as the humanist epos Buddha and the World War II story Paper Fortress also appear. The projected manga imagery has various functions, sometimes several in one scene. Primarily, it illustrates Tezuka's immense oeuvre. In addition, it also addresses the creation and reception of manga and serves to demonstrate the immersive potential of comics. The performers on stage then interact in various ways with the projected manga imagery. Through the interaction, they, amongst other things, create the illusion of being drawn into the images and stories shown on screen, move simultaneously with the projected speed lines, navigate through panel sequences as if they were using touchscreen displays and mime reading the projected manga. Based on a few exemplary scenes, the article now turns to a detailed analysis of the usage of digital comics and their interplay with the actors in the performance.

\section{Immersing oneself into the infinite canvas}

The dance theatre production first uses digitised manga following Astro Boy's initial appearance at the beginning of the performance. In the interplay of performers and projections, this scene shows how Cherkaoui's alter ego immerses himself in Tezuka's manga by reading Astro Boy. On stage, dancer Helder Seabra joins the performer of Astro Boy and takes on his mechanic, robot-like sequence of movements. During the course of the scene, more actors join them and perform the same choreographic elements. At the same time the screen in the

\footnotetext{
${ }^{4}$ This picture was taken during final rehearsals in London. This is why we don't see the original actor of Astro Boy, Kazutomi Kozuki.
} 
background shows juxtaposed digitised comic book pages from various manga by Osamu Tezuka, such as Astro Boy, Buddha, Phoenix, $M W$ and Ayako. These pass by from from left to right in an animated sequence.

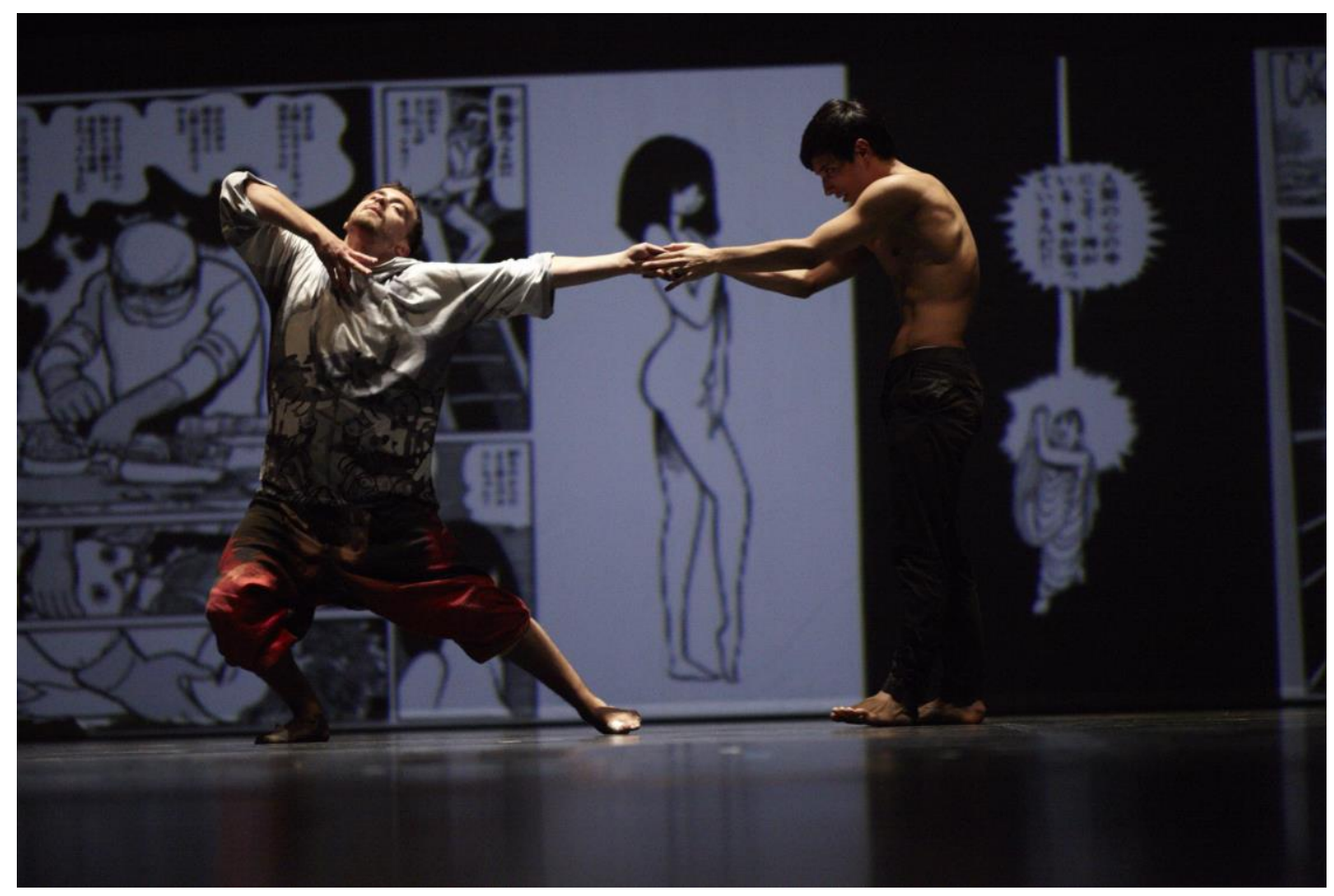

Figure 2. TeZukA, Sidi Larbi Cherkaoui (C) Koen Broos - Eastman 2011. Helder Seabra and another dancer perform in front of the screen depicting digitised manga imagery of Osamu Tezuka.

In this scene, the screen functions as a window - as defined by Scott McCloud - that offers an insight into Tezuka's manga universe. Here, as in other scenes of the performance as well, the mangaka's immense oeuvre is depicted according to the principle of the infinite canvas. However, instead of panel sequences or several single long panels, entire sequentially arranged comic book pages pass by horizontally. Because the imagery is taken from different manga, the sequential arrangement does not reveal narrative coherences, but it instead offers an illustrative insight into the mangaka's seemingly endless oeuvre. In addition to this, the horizontal scroll is part of the animated sequence and thus not triggered by an active reader, who would be in control of the frequency at which the images appear on the display when reading digital comics. As a consequence, the screen shows and makes use of the formal principle of the infinite canvas without effectively implementing its manner of functioning.

\section{Being drawn into the manga}

In another scene, the performance makes use of the animation of entire manga pages and individual comic elements in order to demonstrate how Cherkaoui's alter ego is drawn into Tezuka's manga. In this scene, the screen shows different animated manga pages from Buddha, which pop up for a short moment and then fall over. Helder Seabra (holding a manga book in this scene as well) and another actor stand with their backs to the audience before the screen. Their movements are perfectly coordinated with the animated manga imagery on screen: both actors seem to put up the appearing manga pages and are then knocked over by them. This process is repeated five times until finally, a big panel in the upper half of the last manga page shows a fight scene from Buddha. This time, the images of the comic pages tilt to 
the back, while the frames of the three panels remain standing until their images are no longer visible. After that, the empty frames tilt to the front and fall over the performers. Moving with the empty panels, the performers fall to the ground as well. As soon as Helder Seabra has stood up, he becomes entangled in a martial arts fight in front of the screen with the other actor. During this choreography, the jumps, kicks and punches of the performers correspond with the appearance of animated black speed lines and Japanese ideographs in the style of onomatopoetic sound words on the screen. While new speed lines and ideographs are synchronized with the fighting movements, the ones already on the screen slowly move upwards where they are combined into a huge image of a sitting Buddha.

In this scene, Cherkaoui's alter ego is drawn into the manga, not only in a metaphorical sense, but quite literally. The interaction of performers and animated comic book pages in this scene suggests that Cherkaoui's alter ego and his adversary become manga characters in the last visible panel, which shows a fight scene. While the drawn characters in the projected panel dissolve, the empty frame falls over the performers. In the following fighting choreography, Cherkaoui's alter ego and his adversary become animated characters themselves in the panel that now fills the entire screen. Due to the exact coordination of the activities on stage with the animated speed lines and onomatopoetic ideographs, the scene appears as being part of a completely animated panel in a motion comic. Thus, the scene demonstrates and plays with different possibilities of animation in digital comics: animated pages, the animation of individual elements such as speed lines, and animation of the entire panel content, which here is composed of performers and manga imagery.

\section{Playing with the frames}

The performance also makes use of the animation of elements of comics, especially panels, in other scenes in order to explore the framing of and by comics. This is particularly dominant in a scene in which the screen shows a sketched hand with a pencil, which draws a square frame around the Astro Boy actor who stands in front of the screen. The hand draws further frames and for each new square a performer appears, steps into the sketched frame and seemingly interacts with the panel that surrounds him or her. The movements of the empty frames on the screen and of the performers on stage are perfectly synchronised: in order to stay in their frame, the performers move correspondingly to the panels, which rise and sink as well as grow and shrink. In addition, two performers seemingly create small, sketched squares in their panels and catapult them upwards. During that, the squares grow and turn into more panels, until finally, the screen is filled with comic book pages consisting of empty panels.

In this scene, through the animated panels and the corresponding movements of the performers with the changing positions and forms of the panels on the screen, the performance plays with the frames and the framing of comics in two ways. On the one hand, the actors are framed by panels and thus marked as comic characters. This is made especially clear with Astro Boy, who appears to be captured in a panel on screen by the sketching hand. On the other hand, the actors play and interact with the frames by seemingly manipulating their forms, changing position in accordance with them in front of the screen and tossing them through the air. By doing so, the scene demonstrates and thematises aspects of the function of panel borders in comics as well as the possibilities of the animation of individual elements.

\section{Flipping through comic book pages}

In addition to demonstrating the animation of panel content as well as entire panels, the 
performance presents various procedures by which digital comics organise the sequence of panels and pages. In one scene, which covers Tezuka's experiences in World War II, the screen shows the process of flipping through comic book pages. In this scene, the performers dance a group-choreography at the front of the stage, which consists of martial arts elements. At the same time, the screen depicts different comic book double pages from Tezuka's Paper Fortress in an animated sequence, in which scenes from Japan in World War II can be seen. The individual digitised comic book pages are used as an illustrative backdrop for the choreography. The pages of the manga are not visible long enough for the audience to be able to actually read them. Instead, by showing images such as military aircrafts, the screen merely allows for a grasping of the context at hand. As if by an invisible hand, the comic book pages are turned and a new double page appears for a short moment. This process is repeated several times, before the initially depicted double page is shown again. The flipping through comic book pages, which is triggered by a click or swipe in digital comics, results in the appearance of a new image - here, this is done by an animation that suggests the traditional way of turning pages.

\section{Delivering the panels}

In addition to the animated turning of pages, the performance also uses a different, more complex procedure used in 'panel delivery based comics' (Goodbrey 2013, 190) as a replacement for the traditional page turn in print comics. One type of panel delivery is used in the scene in which the interplay of projections and actors on stage portray an intimate moment between the couple from Phoenix. While two dancers perform a ballet duet at the front of the stage, the screen shows a series of panels in which the couple Masato and Tamami from Phoenix appear. The screen here takes on the function of 'an unmoving stage onto which panels will appear' (Barber 2002, quoted from Goodbrey 2013, 190) in the same manner as used with the digital displays of personal computers and touchscreen devices. The panels, which show the passionate scene between the lovers, appear in an animated sequence one after another from the below right, float over to the left side in an arch and settle in the left corner, slowly combining to form a comic book double page. After this double page is fully visible on the screen, more panels appear on the left and move to the right side until two entire double pages from Phoenix can be seen. The new panels are correlated spatially with the existing ones, overlaying and covering these for a brief moment before finally fitting into position on the screen. Unlike panel delivery in digital comics, in which the appearance of a new panel is triggered by the reader, the screen presents the entire sequence as full animation in this scene. Thus, the screen demonstrates panel delivery as a formal principle without actually executing it, since the 'readers' do not influence the appearance of new panels.

\section{Guiding the viewer}

In the first scene after the break, the screen presents guided view, the mainstream display principle of digital comics, by showing a short story from the first volume of Buddha, in which a rabbit sacrifices itself for an old man. In the beginning of the scene, dancer Guro Nagelhus Schia sits in the front left corner of the stage and looks at the initial pages of the first volume of Buddha, which she holds in her hands. Simultaneously, the same pages are shown on the screen as an animated sequence as it does in guided view, "from a zoomed viewpoint that shows one image at a time. A simple animated transition is then used to show how each image or panel relates to the next in sequence' (Goodbrey 2013, 191). During these animated transitions, one panel disappears and the next one appears. In the process, the 
images adjacent to the visible panels are only displayed as frames without image content. Contrary to guided view, for example as it is used by web comic service comiXology for a variety of remediated print comics, this sequence in the performance is not introduced with a visible comic book page in the beginning and the original spatial design and arrangement of the manga is not maintained. Instead, constant scrolling suggests that all panels are located on a single long page. The sequence ends in a zoom on the same panel that is visible in the manga held by the actress at the front left of the stage: the rabbit that sacrifices itself for an old man becomes a stellar constellation in the sky. ${ }^{5}$

The screen in this scene serves to present the process of reception of the performer Guro Nagelhus Schia. What she reads and in which sequence is demonstrated by the interaction of the animated panels on screen with the movements by Helder Seabra, who stands on the right in front of the screen with his back to the audience during the whole scene. The animated transitions and frequency in which the panels appear on the screen seem to be triggered by his movements. The performer imitates the swiping movements with his body, which a user of a smartphone or tablet would make with his fingers on the touchscreen. The animated transitions on the screen correspond with his movements of the upper body and outstretched arms. When he moves his arms from the left to the right, the zoom on the screen moves in the same direction. While in the guided view of digital comics the animated scrolls are triggered by the reader, in the performance an actor appears to be controlling the pacing of the panels as well as their animated transitions. Thus, he takes the place of the readers of digital comics. At the same time, he embodies guided view itself in his interplay with the animated panels on the screen by imitating the transitions and their directions with his movement. The process of reading of the performer at the front of the stage is thus made visible in this scene and reflected on screen with the help of guided view as a formal principle.

\section{Controlling comics vs. observing animation}

Only in one scene do the performers act as proper readers of the projected manga. In this scene, the screen shows three pages from Buddha, on which a tall man with a huge bulbous nose has a conversation with a fragile old man. The performers Helder Seabra and Guro Nagelhus Schia stand in front of the screen at the beginning of the scene and touch the panels at their margins. As a result, the images - one line of panels at a time - rotate around themselves and then the texts in the speech bubbles appear in English for a short moment before changing back to Japanese. The three pages are now inverted and displayed in Japanese reading style from top right to bottom left. After that, the performers position themselves in front of the screen and watch the image sequences together. Single panels are highlighted by animation from top right to bottom left. They seemingly move out of the page in 3D effect, become larger and briefly overlay the other parts of the panel. The speech bubbles are highlighted one after another in the individual panels following the same principle. As soon as one speech bubble grows in size, the ones in the previous panels shrink. The single elements remain highlighted for the amount of time that is needed for the reception of the images and texts that are shown. The performers look at the highlighted aspects and move away from the panels when they grow on the screen. In this manner, both actors interact with the projected manga pages for the duration of the entire scene.

\footnotetext{
${ }^{5}$ On the recording of the performance in February 2012, a zoom makes visible that Guro Nagehus Schia is reading the first pages of Buddha, which are simultaneously shown on the screen. Whether the audience is able to see that is highly doubtful given the distance between audience and stage.
} 


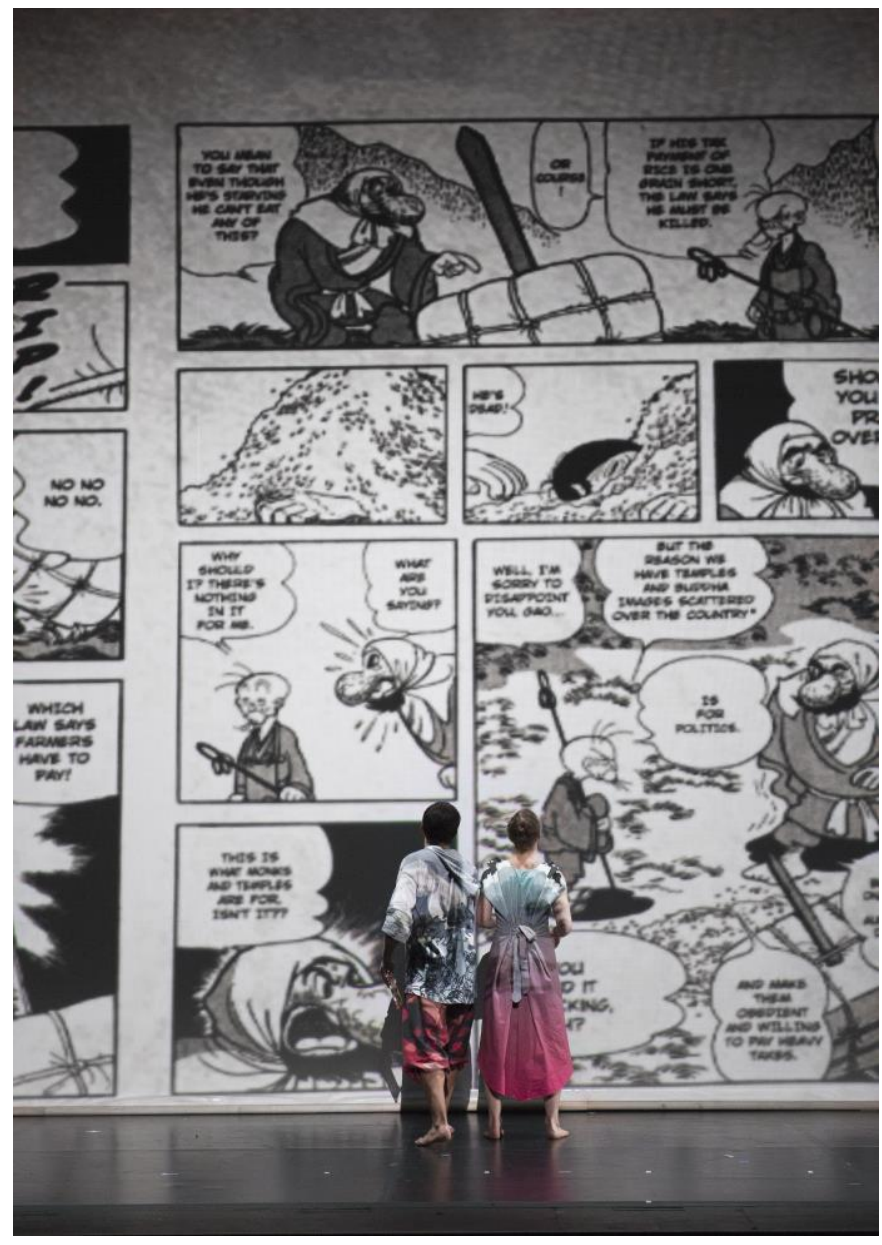

Figure 3. TeZukA, Sidi Larbi Cherkaoui (C) Hugo Glendinning - Eastman 2011.

Guro Nagelhaus Schia and Helder Seabra act as readers of digitised manga pages from Osamu Tezuka's Buddha. ${ }^{6}$

In this scene, the screen demonstrates the succession and duration of the process of reading the projected manga pages by highlighting different elements. At the same time, the performers on stage mime comic readers by following the animated sequences on screen, reacting to the accentuation on screen with their looks and movements. However, they do not trigger the highlighting and cannot influence the frequency of the image sequence. Therefore, in this scene, they mime 'active reader[s] of the comic' (Goodbrey 2013, 195), but are in fact 'passive observer[s] of the animation' (Goodbrey 2013, 195) like the theatre spectators, because they do not execute reader control on the information output that is essential for digital comics. By exposing the process of reading and the specific interaction between screen and performers, this scene in particular points to the fine line between digital comics and full animation. In the entire performance, the screen functions similar to a personal computer or touchscreen device display. However, because the digitised manga are shown as fully animated sequences in all scenes, neither performers nor spectators can actually interact with them. Instead, the performers have to coordinate their movements with the fully animated imagery. Even though the screen shows images that can be described as comics due to their sequential arrangement, the performers or the audience cannot receive these images as digital comics, because they are not able to interact with the display: thus, reader control is missing. As a result, throughout the entire performance, the screen demonstrates the aesthetic principle of digital comics in the form of full animation.

\footnotetext{
${ }^{6}$ The screen shows English captions because the photograph was taken in London, where the performance featured Tezuka's manga in English translations.
} 


\section{Conclusion: Paying homage and performing (digital) comics}

The analysis of the performance shows that the dance theatre production TeZukA is first of all a homage to Japanese comics visionary Osamu Tezuka. By combining theatrical elements with animated video projections, Sidi Larbi Cherkaoui's performance accomplishes a complex involvement with the biography and oeuvre of the famous mangaka. In the interplay of the enactment of his characters on stage and the use of his digitised manga on screen, the performance demonstrates the immersive potential of and fascination with Tezuka's manga. Further, TeZukA displays and choreographs various aesthetic procedures of digital comics. On the one hand, the screen shows animations of individual elements, entire panel content and comic pages as well as panels. On the other hand, digital equivalents to the page turn, such as panel delivery and guided view, are staged in the interplay of the performers with the manga imagery on screen. Beyond paying tribute to Tezuka's life story and work, TeZukA thus makes visible, demonstrates and reflects upon various forms of display and means of reception of digital comics as well as their flowing boundaries with animation.

\section{References}

Balme, Ch. (2008) 'Surrogate Stages: Theatre, Performance and the Challenge of New Media', Performance Research, 13(2), 80-91

Barber, J. (2002) 'The phenomenon of multiple dialectics in comics layout', Master's thesis, London: London College of Printing.

Bukatman, S. (2002) 'Online Comics and the Reframing of the Moving Image', in D. Harries (ed), The New Media Book, London: British Film Institute, pp. 133-43

Campbell, T. (2006) A History of Webcomics, San Antonio: Antarctic Press.

Chapple, F. and Kattenbelt Ch. (2006) 'Key Issues in Intermediality in Theatre and Performance', in F. Chapple and Ch. Kattenbelt (eds), Intermediality in Theatre and Performance, Amsterdam: Rodopi, pp. 11-25

Eisner, W. (2008) Graphic Storytelling and Visual Narrative: Principles and Practices from the Legendary Cartoonist, New York: W. W. Norton \& Company.

Goodbrey, D. M. (2013) 'Digital comics - new tools and tropes', Studies in Comics, 4(1), 185-197

Gravett, P. (2004) Manga: Sixty Years of Japanese Comics, London: Laurence King Publishing.

Gravett, P. (2014) Comics Art, Yale: University Press.

Hammel, B. (2014) Webcomics. Einführung und Typologie, Berlin: Christian A. Bachmann

Jenkins, H. (2012) 'Interview by Julia Round', Studies in Comics, 3(2), 191-202

Kotte, A. (2010) Studying Theatre. Phenomena, Structures and Functions, Wien: Lit Verlag.

McCloud, S. (1993) Understanding Comics, New York: Harper Perennial.

McCloud, S. (2001) Reinventing Comics, New York: Harper Perennial.

Petersen, R. S. (2011) Comics, Manga, and Graphic Novels: A History of Graphic Narratives, Santa Barbara: Praeger.

Rajewski, I. O. (2010) 'Border Talks. The Problematic Status of Media Borders in the Current Debate about Intermediality', in L. Elleström (ed), Media Borders, Multimodality and Intermediality, Houndmills: Palgrave Macmillan, pp. 51-68

Mathias P. Bremgartner is a Ph.D. candidate at the Institute of Theatre Studies, University 
of Berne, Switzerland. From 2009 to 2014, he worked as an assistant lecturer at the Institute of Theatre Studies and was a member of the Graduate School at the Institute of Advanced Study in the Humanities and the Social Sciences, University of Berne. In his Ph.D. project, he explores the interplay of theatre and comics from the perspectives of dramaturgy and intermediality. In addition to his academic activities, Mathias worked as an assistant director at the city theatre of Berne and in public relations at Hebbel-am-Ufer Theatre in Berlin. He is currently dramaturgically advising and managing several Swiss fringe theatre companies.

Email: mathias.bremgartner@itw.unibe.ch 